\title{
O ENSINO DE ADMINISTRAÇÃO NA GRADUAÇÃO: PERCEPÇÃO DE ENFERMEIROS EGRESSOS
}

\author{
Maria Dyrce Dias Meira', Paulina Kurcgant ${ }^{2}$
}

\begin{abstract}
${ }^{1}$ Doutoranda do Programa de Pós Graduação em Enfermagem da Universidade de São Paulo (USP). Docente do Curso de Enfermagem do Centro Universitário Adventista de São Paulo. São Paulo, Brasil. E-mail: dyrcem@yahoo.com.br

${ }^{2}$ Doutora em Enfermagem. Professor Titular do Departamento de Orientação Profissional da Escola de Enfermagem da USP. São Paulo, Brasil. E-mail: pkurcg@usp.br
\end{abstract}

RESUMO: Os paradigmas ideológicos de uma formação integral; a qualidade do profissional que se pretende formar; o compromisso ético, político e técnico, e a complexidade dos processos de trabalho em enfermagem, levam os cursos a repensarem o ensino e sua adequação às Diretrizes Curriculares Nacionais. Esta pesquisa teve como objetivo identificar nos discursos de 32 egressos a importância atribuída ao ensino de administração durante a graduação e correlacioná-los aos pressupostos das diretrizes. Trata-se de um estudo de caso de abordagem qualitativa. Os dados foram coletados através de entrevista semiestruturada e submetidos à Análise de Conteúdo. Segundo os egressos, o ensino de administração deve ter uma carga horária maior; conteúdos mais abrangentes; estratégias diversificadas; reforçar o desenvolvimento de competências, principalmente as ético-políticas e considerar a unicidade entre ensino, pesquisa e extensão. Segundo os egressos as competências gerenciais merecem destaque na reestruturação do currículo de Enfermagem.

DESCRITORES: Enfermagem. Currículo. Administração. Competências profissionais.

\section{TEACHING UNDERGRADUATE MANAGEMENT: PERCEPTION OF NURSING STUDENTS}

\begin{abstract}
The ideological paradigms of a complete nursing background; the professional quality one intends to prepare; the ethical, political, and technical commitment, and the complexity of the nursing work processes cause programs to rethink their teaching and adaptation to Brazilian National Curriculum Guidelines. The objective of this study was to identify in interview conversations with 32 undergraduate nursing students the importance attributed to management classes in their professional preparation and to correlate them to the guidelines' governing principles. This is a qualitative research developed as a case study. The data were collected through semi-structured interviews and submitted to Content Analysis. According to undergraduates, teaching administration must have a greater time load; more encompassing content; diversified strategies; reinforcement of skill development, especially ethical-political skills; and consideration of the union which exists between teaching, research, and community clinical work. According to undergraduates managerial skills deserve special attention in restructuring the nursing curriculum.
\end{abstract}

DESCRIPTORS: Nursing. Curriculum. Management. Professional competence.

\section{LA ENSEÑANZA DE LA ADMINISTRACIÓN EN EL PREGRADO: LA PERCEPCIÓN DE LOS ENFERMEROS EGRESADOS}

RESUMEN: Los paradigmas ideológicos de una formación integral; el tipo de profesional que se desee formar; el compromiso ético, político, técnico y la complejidad de los procesos de trabajo en enfermería llevan a los cursos a reflexionar sobre la enseñanza y adaptación a las Directrices Curriculares Nacionales. Esta investigación tuvo como objetivo identificar en los discursos de treinta y dos egresados la contribución de la enseñanza de la administración en la formación y relacionarlas a los presupuestos de las directrices. Es una investigación cualitativa desarrollada como Estudio de Caso. Los datos fueron recolectados a través de entrevista semiestructurada, y se examinaron a través del Análisis de Contenido. Según los egresados, la enseñanza de la administración debe tener una mayor carga horaria, contenidos más amplios, diversas estrategias; reforzar el desarrollo de competencias, principalmente ético-políticas y considerar la unificación entre enseñanza, investigación y extensión. Los egresados defienden que las competencias gerenciales merecen destaque en la restructuración del curriculum de enfermería.

DESCRIPTORES: Enfermería. Curriculum. Administración. Competencias profesionales. 


\section{INTRODUÇÃO}

A implementação das Diretrizes Curriculares Nacionais (DCNs) nos currículos de graduação constitui um avanço e um desafio para as Instituições de Ensino Superior (IESs). No ensino de Enfermagem, a contribuição das DCNs tem sido principalmente no sentido de orientar e direcionar a formação de recursos humanos capacitados para atender às demandas dos serviços de saúde, cada vez mais complexos. Sua consolidação vem acontecendo articulada aos movimentos de mudanças políticas e pedagógicas que embasaram a Reforma Sanitária Brasileira e o Sistema Único de Saúde (SUS). ${ }^{1}$

A ideologia que permeia o sistema educacional no Brasil tem como paradigma uma formação integral e o processo ensino/aprendizagem preconizado pelo relatório da Comissão Internacional sobre a Educação para o século XXI, conhecido como Relatório DELORS, o qual considera que se deve potencializar as capacidades de aprender a aprender, aprender a fazer e aprender a ser e o aprender a viver junto. ${ }^{2}$

As estratégias de construção de um programa de ensino abrangente e efetivo e que seja compatível com as competências definidas pelas DCNs para os cursos de enfermagem, precisam ser repensadas e re-alinhadas nesta direção. $\mathrm{O}$ desenvolvimento de competências é um dos pressupostos que deve orientar a reorganização da formação profissional do enfermeiro, que busca atender às demandas, deste tempo de mudanças e verdades instáveis. ${ }^{3}$

A formação de enfermeiros bem preparados e articulados com as políticas de atenção à saúde, capazes de aprender a aprender, segundo as dimensões técnico-científicas, sócio-educativas e ético-políticas, tem sido um grande desafio para as escolas formadoras e, em especial, paro o curso de Enfermagem, cenário deste estudo que tem como missão: "Educar no contexto dos valores bíblicocristãos para o viver pleno e a excelência no servir", 4:4 e como visão, "Ser um Centro Universitário reconhecido através da excelência dos serviços prestados, seus elevados padrões éticos e da qualidade pessoal e profissional de seus egressos" . 4:4

A abrangência das DCNs com relação às competências administrativas; os paradigmas ideológicos de uma formação integral; o nível de excelência do profissional que se pretende formar, bem como o compromisso ético, político e técnico expresso na missão e visão do curso em questão justificam os objetivos deste estudo. Por outro lado, as peculiaridades do processo de trabalho gerencial e a complexidade dos processos de trabalho em enfermagem, ampliam a relevância deste estudo.

Visando a busca de respostas às referidas demandas, propomos como objetivos deste estudo identificar nos discursos dos egressos de um Curso de Enfermagem, a contribuição das disciplinas de Administração, na formação do futuro enfermeiro e correlacionar os pressupostos das DCNs referentes ao ensino de administração, com os aspectos apontados pelos egressos.

\section{METODOLOGIA}

Trata-se de uma pesquisa de abordagem qualitativa de caráter descritivo exploratório. $\mathrm{O}$ método adotado foi o Estudo de Caso, utilizado com diferentes propósitos no âmbito das pesquisas qualitativas, destacando o de explorar situações da vida real, cujos limites ou contornos não estão claramente percebidos. ${ }^{5}$ A pesquisa qualitativa "trabalha com o universo de significados, motivos, aspirações, crenças, valores e atitudes, o que corresponde a um espaço mais profundo das relações dos processos e dos fenômenos" .6:21

A unidade-caso da pesquisa é o ensino de administração oferecido em um curso de graduação em enfermagem de um centro universitário privado, confessional e filantrópico. A turma escolhida era composta por 70 estudantes, graduados em 2003. Destes, foi possível localizar e entrevistar 32 egressos. O projeto foi aprovado pelo Comitê de Ética em Pesquisa da Escola de Enfermagem da Universidade de São Paulo, processo No 4872005. Os dados foram coletados, após assinatura do Termo de Consentimento Livre e Esclarecido formulado em conformidade com a resolução do Conselho Nacional de Saúde, № 196, de 10/10/96 e $N^{\circ} 251$ de 07/08/97. Para garantir o anonimato dos sujeitos, eles foram denominados, no estudo, como $E_{1}$ a $E_{32}$. Para a coleta de dados, foi adotada a técnica da entrevista semiestruturada que buscou a caracterização dos sujeitos; o contexto relativo à sua atuação profissional; a percepção quanto ao processo de formação e sugestões para a melhoria do currículo do curso de forma geral, destacandose na análise as falas que fazem referência ao ensino de administração.

Os egressos que participaram do estudo vivenciaram na sua formação o currículo anterior ao proposto pelas Diretrizes Curriculares Nacio- 
nais e, no momento da coleta de dados, estavam inseridos no mercado de trabalho no Município de São Paulo ou em cidades próximas.

Os discursos dos egressos que fazem referência ao ensino de administração foram selecionados e submetidos à técnica da Análise de Conteúdo, permitindo a composição de categorias temáticas elaboradas a partir de suas respectivas unidades de significado. ${ }^{7}$

\section{RESULTADOS E DISCUSSÃO}

O perfil dos entrevistados apresentado a seguir, teve como objetivo contextualizar a análise dos dados para melhor compreensão dos discursos.

Dos 32 sujeitos do estudo, nove eram do sexo masculino, prevalecendo a faixa etária de 27 a 31 anos; 23 eram do sexo feminino com predomínio da faixa etária de 23 a 30 anos; 18 eram técnicos ou auxiliares de Enfermagem antes da graduação; 26 estavam cursando pós-graduação Lato Sensu e um Stricto Sensu. Com relação à área de atuação, prevaleceu a inserção dos egressos em Instituições

\section{Quadro 1 - Categorias e unidades de significado}

\begin{tabular}{|l|l|l|}
\hline \multicolumn{2}{|c|}{ Categorias } & Unidades de significado \\
\hline $1^{\text {a }}$ & Planejamento do ensino em administração & $\begin{array}{l}\text { Carga horária teórico-prática das disciplinas } \\
\text { Conteúdo programático } \\
\text { Estratégias de ensino }\end{array}$ \\
\hline $2^{\mathrm{a}}$ & Competências para a formação do enfermeiro & $\begin{array}{l}\text { Técnico-científicas } \\
\text { Sócio-educativas } \\
\text { Ético-políticas }\end{array}$ \\
\hline $3^{\mathrm{a}}$ & Proposições para otimização do currículo & $\begin{array}{l}\text { Ensino } \\
\text { Pesquisa } \\
\text { Extensão }\end{array}$ \\
\hline
\end{tabular}

Hospitalares públicas ou privadas (26) seguido dos Serviços de Saúde Pública, com destaque para as Unidades Básicas de Saúde (UBS) que trabalham com a Estratégia de Saúde da Família (15); em Ensino Técnico (14) e em Ensino Superior (2). A maioria dos entrevistados relatou ter tido experiência em mais de um local de trabalho (25), e destes, oito assumiram cargos de gerência.

Para a análise dos discursos, tomou-se por base as competências administrativas preconizadas pelas DCNs para os cursos de enfermagem, que apontam para a formação de um profissional generalista, crítico e reflexivo, com competência técnicocientífica, ético-política e sócio-educativa. ${ }^{1}$

As falas abstraídas dos discursos remetem a um confronto com a realidade vivenciada no cotidiano do enfermeiro recém formado, evidenciando as lacunas que deverão ser preenchidas pelo processo de formação.

As categorias que emergiram e as respectivas unidades de significado apresentadas no Quadro 1 , permitem refletir sobre as questões que envolvem o processo de ensino/aprendizagem, com ênfase na área de administração.

\section{Planejamento do ensino de administração}

O ato de planejar pressupõe pensar e prover os meios para se alcançar um determinado objetivo, ou seja, traçar um conjunto de ações concretas, de forma a otimizar os resultados pretendidos. No que diz respeito ao planejamento do ensino em saúde, defende-se a sistematização de práticas pedagógicas vinculadas a ideologias políticas e baseadas na realidade social, visando à construção de uma experiência de aprendizagem que venha contribuir para a formação de profissionais comprometidos com a transformação da sociedade..$^{8-9}$

Neste contexto, o ensino de administração nos cursos de Enfermagem implica no conhecimento das necessidades de saúde da sociedade na qual se insere, bem como na compreensão da complexidade das ações dos enfermeiros objetivando a melhoraria da assistência à saúde. Os egressos, como evidenciado nas categorias apresentadas, destacaram aspectos importantes a serem considerados no planejamento do ensino de administração. 


\section{Carga horária teórico-prática das disciplinas}

Os discursos fazem menção à importância de ser dada carga horária maior às disciplinas de administração. No discurso, a seguir, a ênfase é dada ao desenvolvimento de competências administrativas que fica evidente quando o egresso diz: a Enfermagem é pura administração (E6).

Ter uma carga horária maior e mais aprofundada em algumas outras disciplinas que realmente o mercado necessita e que realmente o curso de enfermagem precisa. [...] o enfermeiro precisa ter um conhecimento maior de administração, ele precisa saber um pouco mais de administração, pois a Enfermagem, na verdade, é pura administração. A carga horária de administração era uma carga horária muito curta em relação às outras disciplinas. Isso deixa o profissional, no mercado, com ansiedade... Por achar que é só assistência quando na verdade o que ele encontra mais é a parte administrativa... (E6).

Existe nas entrelinhas do discurso seguinte, a idéia de horizontalidade do ensino de administração na formação de enfermeiros. [...] a parte administrativa foi pouco, a gente teve administração no $7^{\circ}$ semestre e no $8^{\circ}$ semestre, você fica sete semestres aprendendo a fazer "como", quando você chega no $8^{\circ}$ semestre, você vai aprender a ensinar como fazer "como" (E3).

[...] a parte de administração da graduação... Passa-se pouco tempo... Eu acho que isso poderia vir um pouquinho antes, para ele saber o que vai acontecer, porque quando chega no quarto ano a gente está preocupado com TCC, com formatura... É um conjunto de coisas que não deixa você focar exatamente na administração (E11). Reforçando a idéia anterior, esse outro egresso enfatiza a importância de se começar mais precocemente o desenvolvimento de competências administrativas, a fim de levar o estudante a focar aspectos mais relevantes a serem apreendidos durante o curso.

\section{Conteúdo programático}

O domínio do conhecimento e de tecnologias não são suficientes para um exercício profissional eficiente e eficaz. A interação dos aspectos teóricopráticos com as habilidades interpessoais e o cultivo do pensamento crítico são essenciais para o domínio de uma profissão. Não podemos ignorar os aspectos subjetivos do cuidado, pois estes devem ser considerados na execução de qualquer procedimento técnico. ${ }^{10}$

[...] a gente aprendeu muita coisa na parte de administração, embora eu pense que a administração devesse ter assim, um pouquinho mais de Saúde Pública, porque na prática a gente teve, mas teoricamente falando, ter um pouco mais de administração. Então é isso que eu digo, na parte de administração, acho que tinha que ter... Sei lá, um bloco mais pesado... (E1).

[...] a dificuldade foi na parte administrativa e gerencial, [o ensino] foi voltado mais para a assistência, só no último ano da faculdade a gente teve uma visão mais administrativa, mais assistencial e mais burocrática de como que funcionaria o sistema, e aí a gente acabou se confundindo um pouco... (E31).

A análise dessas falas, quando contextualizadas segundo o currículo que era adotado no curso até o ano de 2003, retrata a deficiência na distribuição e integração dos conteúdos relacionados à administração. A matriz curricular até então, em vigor destinava 305 horas para a disciplina de administração, concentradas apenas no último semestre do curso. ${ }^{11}$

A diversificação dos conteúdos de administração de forma a contemplar todos os processos de trabalho do enfermeiro é evocada nos discursos, quando o egresso faz referência à necessidade de ter [...] um bloco mais pesado de administração e um pouquinho mais em Saúde Pública (E1) e afirma que [...] o ensino foi voltado mais para a assistência... e também quando diz [...] e aí a gente acabou se confundindo um pouco... (E31).

É difícil definir quais são os conhecimentos essenciais, para a formação de um profissional, que sejam abrangentes o suficiente para contemplar os quatro processos de trabalho do enfermeiro: gerencial, assistencial, ensino e pesquisa, em todas as suas especificidades e complexidades. Em estudo realizado com enfermeiros, sobre a visão do processo de trabalho gerencial de enfermagem, foi evidenciado que alguns não têm claro o conhecimento sobre esse processo de trabalho. ${ }^{12}$

É difícil também definir a distribuição e integração dos conteúdos programáticos para o desenvolvimento de competências na formação do profissional de enfermagem que seja apto a atuar na construção de uma sociedade que está em constante transformação, cujos valores são contraditórios, na qual a compreensão das necessidades futuras vai sendo construída a partir de demandas imediatas e transitórias. ${ }^{13}$

Em um artigo, que teve como objetivo descrever as competências gerais citadas nas DCNs e relacionar os conhecimentos necessários para a formação do enfermeiro, as autoras sugerem os conhecimentos apontados nas DCNs, como essenciais para o desenvolvimento de competências ge- 
renciais. Destacam o planejamento, a organização, a coordenação, a liderança e o controle dos serviços de saúde, além dos conhecimentos específicos da área social e econômica em que se insere, a fim de possibilitar o acesso e análise das informações do contexto organizacional. ${ }^{14}$

Em outro estudo sobre esse tema os autores concluem não haver consenso sobre as competências gerenciais indispensáveis ao enfermeiro no contexto atual dos serviços de saúde. Portanto, implementar um programa de ensino que vise ao desenvolvimento de competências gerenciais e, ainda mais, estabelecer os mecanismos necessários para sua efetivação, constitui um grande desafio. $^{15}$

\section{Estratégias de ensino}

Além de apontar como estratégias para o ensino da disciplina de Administração, os estudos de caso e a solução de problemas, o egresso sugere ainda uma interconexão do estudante com a realidade social entendendo que, é a partir deste contato que se estabelece um aprendizado significativo e eficaz.

[...] Eu sei que essa disciplina tem muita teoria, mas vocêprecisa mesmoé de estudo de caso, você precisa de discussão, você precisa de discussão de problemas, de resolução de problemas (E6).

[...] colocar o graduando para tocar nem que seja eventualmente uma equipe simulada, mas para tomar decisões de verdade, na prática... A maior sugestão que eu teria é essa, a de colocar o graduando à prova mesmo, colocá-lo em uma situação difícil, delicada.... E estar ali, é claro, apoiando, guiando, dando dicas de qual melhor caminho a ser tomado, mas colocar à prova mesmo, para administrar. [...] aumentando a carga horária de administração, colocando o graduando estagiando talvez com mais tempo nesta função, para ajudar mesmo, para estar ali do lado do enfermeiro da unidade, observando tudo que acontece naquela unidade, participando talvez de algumas decisões, sugerindo... A gente foi "colocado" em estágio de administração, mas não tivemos esta visão, e muito menos, autonomia. É difícil você dar este tipo de autonomia, pois você não sabe se ele [aluno] está maduro o suficiente ou capacitado o suficiente, para tomar este tipo de decisão, de conduta, mas é importante (E2).

A formação deve ser pautada no contexto da realidade e não centrada em conteúdos descontextualizados dos aspectos sócio, político, econômico e cultural em que a sociedade se organiza. A formação do enfermeiro, em sintonia com os pressupostos e diretrizes do SUS, possibilita vislumbrar uma educação freiriana, que por ser emancipatória e transformadora da realidade permite, ao individuo, responder aos desafios do mundo contemporâneo sendo protagonista da sua própria história. ${ }^{16}$

\section{Competências profissionais do enfermeiro}

As competências e habilidades gerais estabelecidas nas DCNs para os profissionais enfermeiros são - Atenção à saúde - devem estar aptos a desenvolver ações de prevenção, promoção, proteção e reabilitação da saúde, tanto em nível individual quanto coletivo; Tomada de decisões - baseadas em evidências científicas; Comunicação - verbal e não verbal; Liderança - tendo em vista o bem-estar da comunidade; Administração e gerenciamento - tanto da força de trabalho quanto dos recursos físicos e materiais e de informação; Educação permanente - ter responsabilidade e compromisso com a sua educação e o treinamento/estágios das futuras gerações de profissionais. ${ }^{1}$

Estas competências explicitam a amplitude do trabalho do enfermeiro e a necessidade de uma formação abrangente e adequada ao desenvolvimento das mesmas. As competências específicas requeridas para a formação do enfermeiro são detalhadas nas DCNs a partir das gerais e fazem referência às competências técnico-científicas, sócio-educativas e ético-políticas. $\mathrm{Na}$ análise foi possível identificá-las e classificá-las nos discursos dos egressos como apresentados a seguir.

\section{Competências técnico-científicas}

As competências técnico-científicas são entendidas como a capacidade de articular ciência e técnica; de conhecer, intervir e facilitar intervenções nas situações de saúde-doença e ainda a capacidade de atuar em diferentes cenários de saúde. ${ }^{17}$

Sem negar a importância dos outros processos de trabalho do enfermeiro, merecem destaque os discursos que abordam as dificuldades administrativas que comprometem o desempenho profissional inicial do egresso.

Tinha que ter mais hospitais, mais especialidades para o enfermeiro estar vendo... A gente fica muito no "banho de leito", eu acho que tem muitas outras coisas da parte clínica que o aluno pode estar vendo. Teve estágios que eu peguei que foi um mês, um mês e meio, só fazendo estes cuidados básicos de auxiliar de Enfer- 
magem, banho de leito, medicação... E a parte clínica era um pouco deixada de lado, até a parte de administração de enfermagem, você fazer um diagnóstico de enfermagem, uma prescrição... Você tem que aprender também a parte administrativa. Muitas vezes ficar só no cuidado pesado do paciente acaba prejudicando o aluno... (E26).

Mesmo você prestando assistência, você acaba sempre sendo "o administrador". É lógico que você consegue isso no dia a dia, mas quando, já vindo com um conhecimento... Com um embasamento melhor, isso vai melhorar muito mais o seu desempenho. Na minha turma até hoje a gente fala, "nós não tivemos nada de administração". Eu creio que isso dificultou para alguns dos colegas... (E6).

Historicamente o profissional de enfermagem vem se destacando como aquele que, na área de saúde, tem o melhor preparo acadêmico para exercício do gerenciamento das instituições de saúde. Apesar disso, ao se analisar as propostas curriculares praticadas antes das DCNs percebe-se que há uma representação insuficiente das disciplinas e conteúdos voltados ao desenvolvimento de competências técnico-administrativas.

Em discursos já mencionados, os egressos manifestam a importância dessas competências, quando afirmam, [...] a enfermagem, na verdade, é pura administração (E6). Eles também mencionam a percepção dessa lacuna na formação quando reconhecem que no curso houve uma preponderância do ensino voltado à assistência e ao cuidado direto do doente em detrimento da formação para o exercício da gerência. [...] ficar só no cuidado pesado do paciente acaba prejudicando o aluno... (E26).

Outro aspecto importante percebido pelo egresso é o imbricamento dos processos de trabalho assistencial e gerencial [...] mesmo você prestando assistência, você acaba sempre sendo "o administrador" (E6). O gerenciamento, como processo de trabalho instrumental, interfere significativamente nos outros processos de trabalho do enfermeiro, devendo, portanto, permear todas as etapas do ensino de graduação. Ressalta-se aqui a importância da integração dos conteúdos, técnico-assistenciais e administrativos, no desdobramento de programas de ensino que resulte em um aprendizado significativo.

\section{Competências sócio-educativas}

As competências sócio-educativas pressupõem a capacidade de atuar e promover a responsabilidade social e o compromisso com a cidadania; refletir e promover a reflexão e a transformação da realidade; incentivar e promover condições para o aprendizado contínuo. ${ }^{17}$

Os egressos demonstram ter percepção clara deste aspecto da formação e qual a contribuição, do curso, no desenvolvimento de competências sócio-educativas. Destacam como um dos elementos facilitadores o saber relacionar-se com os pacientes e com a equipe de enfermagem.

[...] na faculdade eles pregam muito a humanização, se preocupar com o paciente, com o que ele pensa... Como ele está se sentindo... E a gente aprende muito a dar valor para isso. Essa parte da humanização com o paciente, se preocupar com o paciente... (E30).

A maior facilidade e que eu aprendi mais na faculdade foi de relacionamento, e com relacionamento você acaba conseguindo tudo que você deseja de uma equipe. Vocêtem que ter a postura de enfermeiro de comandante da equipe, então na escola você aprende bastante isso de relacionamento com a equipe. Não de relacionamento autoritário, mas de saber ouvir as equipes, identificar onde estão os problemas e buscar as soluções desses problemas, ouvindo cada membro da equipe porque cada um tem uma idéia (E26).

Em contrapartida, nos discursos seguintes, os egressos retratam como dificuldade o relacionamento com a equipe multidisciplinar, sugerindo a necessidade de se repensar o processo de trabalho do enfermeiro, em suas diversas áreas de atuação. Muitas vezes não estão muito claras as concepções do saber, a área do conhecimento, os espaços profissionais e os papéis de cada um nas equipes de saúde. O enfermeiro deve ter bem definido o seu objeto de trabalho e campo de atuação, a fim de não incorrer em falha ética e, assim, propiciar um clima harmonioso na equipe ${ }^{18}$ como sugere a fala: ás vezes é muito difícil você estar se relacionando com a equipe. Eu acho mais difícil trabalhar com as pessoas, com os médicos, com a equipe multiprofissional, fisioterapeuta, fonoaudióloga. A questão burocrática começa a dificultar, devido a pessoas que não facilitam e às vezes dificultam o nosso trabalho, algo que poderia ser muito mais simples as pessoas transformam em uma coisa de outro mundo (E30).

$\mathrm{O}$ aprender a conhecer e o aprender a fazer são indissociáveis. Esta concepção demanda que a formação técnico-profissional deve estar atrelada ao desenvolvimento de competências sócioeducativas, destacando habilidades especificas do processo gerencial como: aptidão para o trabalho em equipe, capacidade de iniciativa e gosto pelo risco sem considerar a formação profissional como um fim em si mesma. ${ }^{2}$ 


\section{Competências ético-políticas}

As competências ético-políticas são compreendidas como a capacidade de construir coletivamente os processos de trabalho; de decidir eticamente valorizando a solidariedade; de ouvir e de compartilhar decisões; de gerenciar conflitos identificando seus determinantes. ${ }^{17}$

Em suas percepções do processo de formação, os egressos demonstram apreciar a forma como a faculdade priorizou o ensino de valores. Entre os princípios que sustentam os pilares educacionais das escolas confessionais onde se insere o curso de enfermagem em questão, destaca-se o ensino de valores. Estes são defendidos como a axiologia que deve permear o currículo escolar e influenciar um viver coerente com os princípios básicos da ética cristã valorizando o ser humano como membro de uma comunidade, com responsabilidades e direitos para com o meio ambiente, a vida e a família. ${ }^{19}$

Quando o egresso se expressa em defesa destes valores e reconhece a sua importância no desempenho das suas atividades rotineiras, percebe-se uma formação coerente com estes princípios.

[...] a responsabilidade era incutida no aluno, o fato de ter que usar uniforme, de ter horário, de ter controle das faltas, eu olho assim e vejo a cobrança. A gente se lembra do professor " $X$ ", todo mundo falava dele, mas todo mundo respeitava, Responsabilidade é tudo, se você é responsável você age com ética, você age com cuidado no paciente, você faz o que tem que ser feito. Você sabe que ninguém está te olhando, mas você é responsável... Você aprendeu fazer direito, você vai fazer, você vai aprender a cobrar isso também dos seus funcionários (E3).

A interação professor-aluno deve visar à construção do conhecimento, estimular a reflexão, a capacidade de observação, de análise, de crítica e a autonomia. Para que o aluno possa transformar a prática e reexaminar a sua visão de mundo ele precisa se apropriar dos diversos saberes, incluído o saber ser e conviver num plano ético e moral bem definidos. ${ }^{20}$

[...] A faculdade me daria também respaldo éticomoral... E isto fez com que eu adentrasse no mercado de trabalho com uma outra visão, a missão de levar o conforto às pessoas, isto sem dúvida é o grande diferencial que a faculdade oferece aos seus alunos, aos seus egressos (E15).

Todas as instituições falam que dão preferência aos formandos da escola pela postura que eles têm, pois se erram, têm consciência do erro. Querem sempre melhorar, estão sempre em busca de crescimento, de pós-graduação (E25).

O ensino com valores voltados à humanização é destacado como um diferencial positivo na formação dos egressos deste curso. Reconhecem que a prática de um cuidado integral não pode prescindir da humanização, pois o trabalho do enfermeiro no cuidado em saúde, a partir de uma prática humanizada, dá sentido à ação e identifica a finalidade do trabalho. Tem também como referência mobilizar os recursos de forma combinada, a fim de produzir ações em saúde e em enfermagem, coerentes com o projeto político proposto. ${ }^{21}$

\section{Proposições para otimização do currículo}

A indissociabilidade entre ensino, pesquisa e extensão é preconizada pelas DCNs. A conexão entre estes três eixos deve nortear o planejamento curricular, e é defendida pelos egressos como demonstrado nas unidades de significado.

\section{Ensino}

Para que o ensino aconteça tem que haver aprendizagem. Aprender é reconstruir, para isso é preciso desconstruir continuamente o saber, a fim de possibilitar a construção de novos conhecimentos que vão levar a uma aprendizagem

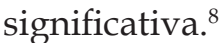

[...] e eu acho que a parte administrativa deveria ter mais. Deve melhorar agora nas próximas turmas, devido ao estágio supervisionado, aquele da administração que o aluno fica um ano, no quarto ano, sozinho. Isso a gente não teve (E17).

[...] deveria melhorar o preparo do aluno graduando para o mercado. Enfocando o que éo mercado. Preparar para a realidade do que é lá fora, tanto na iniciativa privada, "top" de linha, como no público (E9).

Deveria relacionar mais as matérias, não deixar para o último ano... Sistematização da Enfermagem com a administração, com a postura, com tudo ali, com a ética. E foi uma coisa que o meu grupo percebeu que só no último ano que foi ocorrer isso (E12).

Nos discursos a seguir, nota-se predominância nas falas, que sugerem mudanças no ensino da disciplina de administração, principalmente no que diz respeito à liderança.

[...] tinha que ter mais intercâmbio entre as instituições de saúde e o pessoal do estágio. Fica muito desconexa a equipe de estágio com o hospital. Quando você chega ao hospital os funcionários pensam que você 
vai ser a mão de obra para estar ajudando eles a fazerem os cuidados de enfermagem ali. Você tem que aprender também a parte administrativa, a parte clínica, entender um pouco do processo da doença, associar o que você aprendeu na teoria com o que você esta vendo ali na prática. Muitas vezes ficar só no cuidado pesado do paciente acaba prejudicando o aluno, ele sai sem muita bagagem da parte prática, (administrativa e clínica) fica muito na teoria (E26).

[...] eu vejo que nos precisaríamos sair da formação com uma base muito maior, e o que eu acho que é mais importante: a formação deve promover uma abertura da nossa visão, uma visão ampla, "holística", do que é em si trabalhar na enfermagem porque, na verdade, nós atuamos muitas vezes na base assistencial, mas nós atuamos muito mais como lideres. [...] dentro dessa liderança eu vejo que muita coisa precisa ser "burilada", reformulada ou reconceituada dentro dos conceitos novos... É isso que a gente precisaria dar uma retocada (E20).

É ponto expressivo nos discursos, a necessidade de aprofundamento do ensino de administração, com destaque à questão da autonomia que deve ser estimulada, no estudante, sem prescindir do suporte e do acompanhamento do professor.

A maior sugestão que eu teria é essa, a de colocar o graduando à prova, colocá-lo em uma situação difícil, delicada.... E estar ali, é claro, apoiando e guiando. A gente foi colocado em estágio de administração, mas não tivemos esta visão, e muito menos, autonomia. É difícil você dar este tipo de autonomia, pois você não sabe se o aluno está maduro ou capacitado o suficiente, para tomar este tipo de decisão, ou conduta, mas é importante (E2).

Em pesquisa realizada em uma universidade privada do Rio Grande do Sul, foi identificado que a aprendizagem na área de gerenciamento é a maior deficiência na formação dos enfermeiros egressos. Segundo a pesquisadora, tal deficiência foi evidenciada, também, em pesquisa realizada com os empregadores desses egressos. ${ }^{13}$

A importância de um ensino melhor, nesta área, é referendada pelas DCNs ao considerar que, as competências gerais para a formação do enfermeiro, devem privilegiar as que se relacionam com os saberes oriundos da ciência da Administração, como tomada de decisão, comunicação, liderança, administração e gerenciamento. ${ }^{1}$

\section{Pesquisa}

A pesquisa é um dos pilares que sustenta a construção de um aprendizado significativo, pois permite ao estudante exercitar a curiosidade científica que lhe possibilita aplicar o aprendizado de maneira efetiva, retroalimentando a cadeia do conhecimento. $\mathrm{O}$ egresso sugere que o curso faça maiores investimentos no sentido de estimular o aluno a buscar na pesquisa, uma forma de avançar no conhecimento.

[...] incentivar mais cursos extracurriculares. Eu acho que a faculdade não incentivou muito a iniciação científica, eu acho que tiveram falhas. É, incentivar um banco de horas de cursos para os alunos. [...] colocar mais pessoas disponíveis para estar dando orientação científica... E pessoas preparadas para isso. Que o incentivo seja maior (E19).

Apesar de abordarem de forma sucinta o processo de trabalho - pesquisar, os egressos o mencionam como um dos aspectos significativos na formação do enfermeiro. O discurso apresentado a seguir mostra contradições, pois o egresso reconhece a contribuição da faculdade nessa área, ressaltando a importância, dessa competência, para o exercício profissional. Ele usa a expressão "bem pincelada" denotando a necessidade de ser aprofundado o ensino nessa área, dando subsídios e consistência para o desenvolvimento da autonomia e consequente desempenho das competências técnico-científicas, sócio-educativas e ético-políticas.

Eu acho que a pesquisa deveria ser mais aprofundada. Investir mais na pesquisa, pois hoje conta muito. [...] lá onde eu trabalho, eles investem muito na pesquisa. Então nisso [a faculdade] contribuiu... A pesquisa eu acho que foi bem pincelada. [...] hoje a gente desenvolve através da necessidade. Eu não sei como "bolar" uma boa pesquisa, porque eu não tive uma boa formação na área de pesquisa (E21).

"Ao ser produzido, o conhecimento novo supera o outro que antes foi novo e se fez velho e se 'dispõe' a ser ultrapassado por outro amanhã'. ${ }^{22: 28}$ O ensinar, aprender e pesquisar se articulam com os dois momentos do ciclo gnosiológico: quando se ensina e se aprende o conhecimento já existente, e quando se trabalha a produção do conhecimento ainda não existente. Pois, "Não há ensino sem pesquisa e nem pesquisa sem ensino". 22: 29

\section{Extensão}

As DCNs prevêem o reconhecimento de habilidades e competências extra-escolares, segundo a estrutura geral do curso. O curso deve valorizar a inserção do aluno em atividades de estágios extracurriculares, estimulando sua participação 
em programas da própria escola sendo tais atividades, reconhecidas, pelo egresso, como de grande importância para a sua formação. ${ }^{23}$

A melhor coisa que eu tive foi ter feito no último ano da faculdade, o estágio extracurricular, em "nome da instituição" pelo CIEE [Centro de Integração Empresa-Escola], com uma equipe muito boa para trabalhar, eu aprendi muito (E14).

Embora, o CIEE seja uma iniciativa do empresariado brasileiro, as escolas que estão vinculadas a este centro oferecem oportunidades aos seus estudantes que são comparadas aos programas de extensão universitária, pois propiciam condições necessárias ao desenvolvimento de competências em todas as suas dimensões.

A importância de o estudante reconhecer a complexidade da condição humana, não pode ser apreendida dissociada dos elementos que a constituem e, entre estes, o envolvimento comunitário que proporciona um sentimento de pertença e de responsabilidade social no educando. É papel da educação do futuro preservar a unidade da espécie humana, sem, contudo, permitir que se apague a idéia de diversidade. Compreender é também aprender e reaprender incessantemente, pois a compreensão é ao mesmo tempo meio e fim da comunicação humana. ${ }^{24}$

No discurso seguinte, percebe-se que o egresso reforça estas idéias quando diz que: a faculdade ficou restrita à academia. O aluno não está inserido no trabalho comunitário durante a época acadêmica, o relacionamento com a comunidade falta um pouco para a faculdade. [...] lidar com a população pode dar um pouco de dificuldade porque é um outro mundo lá fora. O estudante tem um estilo e eles têm outro diferente, a própria linguagem, o jeito de tratar, dá diferença, às vezes dá até um choque. [...] fazer mais trabalhos com a comunidade, fazer o aluno ter mais contato, vivência, conhecer o dia a dia deles também. Isso vai capacitar bastante em qualquer lugar que ele for... Em São Paulo ou em outras regiões... Se tivesse um contato antes [com a comunidade], facilitaria bem mais. Se pudesse melhorar, ajudaria bastante (E4).

O estudante de enfermagem deve interagir de forma efetiva com sua clientela, principalmente com os mais carentes e oprimidos, a fim de adequar os cuidados às necessidades de saúde, priorizando o respeito pelas diferentes heranças culturais. ${ }^{13}$

Na tese intitulada - Saberes e competências na formação dos enfermeiros em Saúde Coletiva, a autora identifica na fala dos professores, sujeitos da pesquisa, a "necessidade de dar mais visibilidade ao trabalho de Enfermagem com as ações gerenciais, e a manutenção da essência da Enfermagem com o 'cuidar' em suas diferentes dimensões" ${ }^{25: 128}$ Essa autora evidencia, no discurso dos docentes, a necessidade de uma formação profissional cada vez mais voltada para a realidade concreta e, para tanto, sugere a introdução de novas abordagens metodológicas, como: "inserir o aluno na realidade o mais cedo possível; trabalhar a partir de situações-problema reais, problematizadas e analisadas à luz de referenciais teóricos atualizados; praticar uma avaliação formadora em situações de trabalho; conseguir uma menor compartimentalização das disciplinas". 25:124

\section{CONSIDERAÇÕES FINAIS}

Das reflexões sobre os desafios de uma formação abrangente e do pensar em uma reformulação de currículo que contemple a organização dos conteúdos tidos como essenciais e contextualizados com as exigências do mercado de trabalho em saúde, surgem questões que merecem um aprofundamento a priori. Considerando o crescente avanço tecnológico e cientifico, como deve ser conduzido o processo de formação do enfermeiro? Quais serão os conhecimentos, habilidades e atitudes que os estudantes deverão desenvolver, durante a graduação, para desempenharem, com competência, os processos de trabalho que venham a ser requeridos ao ingressarem na profissão?

Pressupondo que as competências administrativas são necessárias em todos os processos de trabalho do enfermeiro cabe as escolas formadoras a responsabilidade de propiciar, ao estudante, as condições para o desenvolvimento dessas competências,

Nesse contexto, os egressos sugerem o fortalecimento da prática interdisciplinar e apontam a necessidade de otimizar a distribuição de conteúdos e de carga horária das disciplinas que são destinadas à formação de competências administrativas. Sugerem, ainda, a aproximação do estudante à realidade profissional, com estágios em instituições diversas, o mais precocemente possível, propiciando as condições geradoras de um aprendizado significativo e consistente, capaz de mobilizá-los a buscar novos conhecimentos numa perspectiva contextualizada de forma a garantir um desempenho profissional competente, determinante e determinado pelas transformações sociais.

Consideram assim, que os conteúdos da administração devam permear, ao longo do curso, a concretização do currículo proposto e fazer a in- 
terlocução com outras disciplinas, de tal forma que promova um ensino integrado e contextualizado.

Essas reflexões mostram que as dificuldades, enfrentadas pelos egressos no seu cotidiano de trabalho e que podem ser dirimidas por um programa de ensino planejado e concretizado a partir do preconizado pelas DCNs. Ressalta-se como contribuição deste estudo, a importância da participação efetiva dos egressos nos processos de avaliação do ensino oferecido pelas IESs, pois é no cotidiano profissional que a formação é efetivamente consolidada.

\section{REFERÊNCIAS}

1. Conselho Nacional de Educação (BR), Câmara de Educação Superior. Resolução CNE/CES N ${ }^{\circ}$ 3, de 7 de novembro de 2001. Institui Diretrizes Curriculares Nacionais do Curso de Graduação em Enfermagem. Diário Oficial da República Federativa do Brasil, 9 Nov. 2001. Seção 1, p. 37.

2. Delors J. Educação: um tesouro a descobrir. Relatório para a UNESCO da Comissão Internacional sobre a Educação para o século XXI. $3^{\text {a }}$ ed. São Paulo (SP): Cortez; 1999.

3. Faustino RLH, Moraes MJB, Oliveira MAC, Egry EY. Caminhos da formação de Enfermagem: continuidade ou ruptura?. Rev Bras Enferm. 2003 Jul-Ago; 56(4):343-7.

4. Centro Universitário Adventista de São Paulo (UNASP). Regimento Geral. São Paulo (SP): UNASP; 2001. p.4.

5. Yin RK. Estudo de caso: planejamento e métodos. $3^{\mathrm{a}}$ ed. Porto Alegre (RS): Bookman; 2005.

6. Minayo MCS, organizadora. Pesquisa social: teoria, método e criatividade. $15^{\mathrm{a}}$ ed. Rio de Janeiro (RJ): Vozes; 2000.

7. Bardin L. Análise de conteúdo. Lisboa (PT): Edições 70; 1977.

8. Demo P. Metodologia do conhecimento científico. São Paulo (SP): Atlas; 2000.

9. Batista NA. Planejamento na prática docente em saúde. In: Batista NA, Batista SH, organizadores. Docência em saúde: temas e experiências. São Paulo (SP): Senac; 2004. p.35-56.

10. Bork AMT, Minatel VS. Enfermagem de excelência: da visão à ação. Rio de Janeiro (RJ): Guanabara Koogan; 2003.

11. Centro Universitário Adventista de São Paulo. Projeto Pedagógico do Curso de Graduação em
Enfermagem. São Paulo (SP): UNASP 2001b.

12. Sanches VF, Christovam BP, Silvino ZR. Processo de trabalho do gerente de enfermagem em unidade hospitalar - uma visão dos enfermeiros. Esc Anna Nery Rev Enferm. 2006 Ago; 10(2):214-20.

13. Cunha AZS. Atores e práticas na formação do enfermeiro: avaliação em perspectiva participativa [tese]. Florianópolis (SC): Universidade Federal de Santa Catarina. Programa de Pós-Graduação em Enfermagem; 2004.

14. Peres AM, Ciampone MHT. Gerência e competências gerais do enfermeiro. Texto Contexto Enferm. 2006 Jul-Set; 15(3):492-9.

15. Cunha ICKO, Neto FRGX. Competências gerenciais de enfermeiras: um novo velho desafio?. Texto Contexto Enferm. 2006 Jul-Set; 15(3):479-82.

16. Aschidamini IM, Saupe R. Competências na promoção em saúde da família: uma perspectiva de docentes e acadêmicos de Enfermagem [dissertação]. Itajaí (SC): Universidade do Vale do Itajaí. Programa de Mestrado em Saúde e Gestão do Trabalho; 2005.

17. Meira MDD, Kurcgant P. Evaluation of nursing education according to the perception of exstudents. Acta Paul Enferm. 2008; 21(4):556-61.

18. Duarte MJRS. Enfermagem fundamental: realidade, questões e soluções. São Paulo (SP): Atheneu; 2001.

19. Confederação das Uniões Brasileiras da Igreja Adventista do Sétimo Dia. Pedagogia Adventista. Tatuí (SP): Casa Publicadora Brasileira; 2004.

20. Sordi MRL, Bagnato MHS. Subsídios para uma formação profissional crítico-reflexiva na área de saúde: o desafio da virada do século. Rev Latino-am Enfermagem. 1998 Abr; 6(2):83-8.

21. Kawata LS, Mishima SM, Chirelli MQ, Pereira MJB. O trabalho cotidiano da enfermeira na saúde da família: utilização de ferramentas da gestão. Texto Contexto Enferm. 2009 Abr-Jun; 18(2):313-20.

22. Freire P. Pedagogia da autonomia: saberes necessários à prática educativa. $33^{\mathrm{a}}$ ed. São Paulo (SP): Paz e Terra; 2006.

23. Nimtz MA. O significado de competência para o docente de Administração em Enfermagem [tese]. São Paulo (SP): Universidade deSão Paulo. Programa de Pós-Graduação em Enfermagem; 2003.

24. Morin E. Os sete saberes necessários à educação do futuro. Trad. de Catarina Eleonora F. da Silva e Jesanine Sawaya. $5^{\text {a }}$ ed. São Paulo (SP): Cortez; 2002.

25. Faustino RLH. Saberes e competências na formação dos enfermeiros em Saúde Coletiva [tese]. São Paulo (SP): Universidade de São Paulo. Programa de PósGraduação em Enfermagem; 2004. 